\title{
Research on Environmental Design Curriculum Plan Based on Profession Ethics in Design
}

\author{
Yang Zhang ${ }^{1, a}$ and Shuofang Liu ${ }^{1, b}$ \\ ${ }^{1}$ National Cheng Kung University \\ No.1, University Road \\ Tainan City 701, Taiwan (R.O.C) \\ a $502148688 @ q q . c o m,{ }^{b}$ liusf@mail.ncku.edu.tw
}

\begin{abstract}
As China's real estate industry develops at a rapid pace, the demand for environmental design professionals has greatly increased, while the problem that how to cultivate their profession ethics in the education phase has gradually become the public focus. However, the current design curriculum syllabus has not yet explored the relationship between professional ethics and the courses by scientific methods, thus resulting in graduates potentially having a cognitive gap on profession ethics. This study first researched the requirements in the industry and by customers. Thereafter, a graph was drawn which is the importance of the code of professional ethics of environmental designers in weight order, through descriptive statistics, and subsequently another was gained which is the importance of compulsory courses in weight order in line with environmental designers' profession ethics education by FuzzyQFD. Finally, the paper put forward some subjects which should be emphasized and strengthened in the curriculum of environmental design so as to nurture student's profession ethics, and gave some suggestions for adjustment. It is hoped that the results of this study can be used as a reference for design curriculum planning and professional ethics education.
\end{abstract}

Key words: ethics, environmental design curriculum, FuzzyQFD

\section{Introduction}

With the rapid development of society and technology, the design industry has gradually become mature and diversified. Thus, the social demand for design personnel should also be changed according social changes[1]. Since the demand for design personnel is rapidly growing, many education units in design industry might simply focus on the training of design skills but ignore professional ethics' cultivation. Freeman (8.2000) once argued that professionals with moral outlook, when facing ethical problems, would think systematically, which shows the significance of professional ethics. While in engineering, medicine, and some other fields profession ethical education has already been launched [2,3]. This clearly shows the importance of profession ethics education in tertiary education.

Quality Function Deployment is a mature multi-level deductive analysis method, which has been widely used in scientific research in various industries. On the other hand, it can, if being used with other research methods, improve the actual efficiency and accuracy of QFD in research, which is one of its advantages.

To sum up, this study will draw up a designers' code of professional ethics and behavior by consulting literature reviews and interviewing relevant experts. On the other hand, a QFD expert group would be formed and the cognition level of profession ethics is to be calculated by descriptive statistics. Thereafter, the cognitive level of ethical code and design professional courses would be put into the QFD quality house. Finally, the result which is the level of importance of design courses based on professional ethical codes of conduct are obtained. It is hoped that this study can provide guidance for consideration in the curriculum planning of design, and a clear elemental quantitative method for future research in design education.

\section{Literature Review}

\section{A. Quality Function Deployment (QFD)}

Quality function deployment is a method developed and successfully applied by AKAO in 1966 [5]. It can effectively help enterprises collect and realize customer demand [6].It has been widely used. For example, Liu and Zhang have applied QFD method to the development of creative products and achieved remarkable results; Chen, Yeh and other scholars [7] have used QFD to evaluate and improve the service quality of fast food chain restaurants; Liu, Cheng, Lee and Gau [8] also have applied QFD to studying industrial packaging for safe delivery. QFD technology focuses on the construction of quality house (HoQ), because HoQ can effectively link demand with technology [9]. In this study, QFD method will be used to explore the relationship between design curriculum and the professional ethics of designers.

\section{B. Fuzzy}

Zadeh [10] once proposed that human reasoning is essentially not clear, for which it is necessary to analyze things with vague concepts. And Fuzzy Theory provides a solution to these complicated and ambiguous problems which are usually caused by a lack of accuracy[11]. Fuzzy Theory often uses fuzzy linguistic variables to simulate human cognition process [12]. In this study, we will use Fuzzy Theory to construct the relationship matrix between moral principles and curriculum, 
and get the final weight value.

\section{Research process and results}

In this study, identification and standards of professional ethical behavior of designers were discussed by studying eight international organizations, including the ICOGRADA (International Council of Graphic Design Associations), the ICSID (International Council of Societies of Industrial Design), the IFI (International Federation of Interior-Designers), the IDSA (Industrial Designers Society of America), the ASID (American Society of Interior Designers), the AIGA (American Institute of Graphic Arts), and the DIA .(Design Institute of Australia) Thereafter, through KJ Method, this study has sorted out eight kinds of professional ethics of designer, which are: designer for: C1-Client and Employer (10 items); C2-Other Designers (10 questions); C3-Salary (7 questions); C4-Occupation (9 questions); C5-Reputation and Publicity (3 questions); C6-the Public (3 questions); C7-Society and Culture (4 questions); C8-Responsibility to the Environment(2 questions).

\section{A. Descriptive Statistics of Profession Ethical Behavior Cognition of Designers}

In this study, the author produced a questionnaire survey based on the eight kinds of professional ethics of designer. There are 31 questions in the questionnaire, and all subjects received a professional design training in higher vocational schools, with a more 2-year-experience in the industry. 93 questionnaire copies were sent out with a timeframe of two months. After eliminating 25 invalid questionnaires, 68 questionnaires were obtained. The recovery rate of valid questionnaires was $73 \%$. Then, by using SPSS statistical software to calculate descriptive statistics, the average number of the designer's perceptions of the code of professional ethics and behavior was obtained, as shown in Table 1 . In the next stage, the average number of cognition would be brought into QFD quality house as weight value for each cognition to conduct research.

Table 1.

Descriptive statistics of professional ethics of designers

\begin{tabular}{ccc}
\hline & Average & $\begin{array}{c}\text { Standard } \\
\text { Deviation }\end{array}$ \\
\hline C1 & 4.0861 & 0.49001 \\
C2 & 4.2941 & 0.66487 \\
C3 & 4.2059 & 0.63619 \\
C4 & 4.2605 & 0.50398 \\
C5 & 3.9191 & 0.58342 \\
C6 & 4.1814 & 0.58003 \\
C7 & 4.2316 & 0.55536 \\
C8 & 4.2868 & 0.65401 \\
Integra1 & 4.1832 & 0.44258 \\
value & & \\
\hline
\end{tabular}

B. QFD fuzzy relation matrix of ethics and design courses

At this stage, the descriptive statistical results of the designer's perception of professional ethics and codes of conduct are put into the left wall of the quality house. On the other hand, after focus group discussion, the undergraduate curriculum of environmental design major of a university in China was finally selected and put into the ceiling part of QFD quality house. Considering that the undergraduate curriculum contains relevant basic or general courses, and this study focuses on the relationship between design curriculum and the professional ethics of designers.

At the same time, in the process of undergraduate design education, many courses are divided into several semesters because of the large amount of lessons. For these kinds of courses, the focus group also uses $\mathrm{KJ}$ method and expert discussion method to converge all courses, and finally $\mathrm{X}$ courses are generalized, which are: L1.Basic Painting, L2.Composition, L3.History of Design, L4.Basic Drawing, L5.Computer Aided Design, L6.Ergonomics, L7.Public Interior Design, L8.Model Design and Production, L9.Environmental Thematic Design, L10.Regional Environmental Design, L11.Landscape Planning and Design, L12.Lighting Design, L13.Project Budget, L14.Design Planning.

Before applying the theory of fuzziness to the evaluation of fuzzy relations, relevant fuzziness must be formulated. The relevant evaluation for this study is not $1,3,9$, but the fuzzy number of the semantic variables represented by 1,3 and 9 . In this study, the focus group and experts had an in-depth discussion, and had worked out the fuzzy numbers that 1, 3 and 9 represents according to the actual situation: 1 is weak correlation; 3 is medium correlation; 9 is strong correlation. The specific fuzzy numbers can be seen in Table 2 .

Table 2.

Definition of variables in fuzzy number language

\begin{tabular}{lc}
\hline language variables & Fuzzy numbers \\
\hline Weak correlation $(1)$ & {$[0.00 ; 0.10 ; 0.40]$} \\
Medium correlation $(3)$ & {$[0.30 ; 0.55 ; 0.70]$} \\
Strong correlation $(9)$ & {$[0.60 ; 0.90 ; 1.00]$} \\
\hline
\end{tabular}

After linguistic variables of fuzzy numbers have been decided, the author has established the fuzzy relation matrix with five experts(with the author included), who have worked in design industry for more than five years. The fuzzy relation matrix can be obtained by evaluating the fuzzy relation between the moral criterion and the design course by combining the variables with the weight of the moral criterion. Details are shown in Table 3. Table 3.

Fuzzy relation matrix between professional ethical standards and the curriculum

\begin{tabular}{llllllllllllllll}
\hline \multicolumn{10}{c}{ Rating L1 L2 L3 L4 L5 L6 L7 L8 L9 L10 L11 L12 L13 L14 } \\
\hline C1 & 4.0861 & 1 & 3 & 1 & 9 & & 1 & 9 & 3 & 9 & & & 9 & 9 & 3 \\
C2 & 4.2941 & 9 & 3 & & 9 & 9 & & & 3 & 3 & 3 & 9 & & & 3 \\
C3 & 4.2059 & 3 & & 3 & 3 & & 9 & & 9 & 1 & 1 & 3 & 9 & 3 \\
C4 & 4.2605 & 9 & 9 & & 9 & 9 & 1 & 1 & 3 & 3 & 3 & & 9 & 1 \\
C5 & 3.9191 & 1 & & 1 & & 1 & & 3 & 9 & 3 & 9 & 3 & & & 3 \\
C6 & 4.1814 & & & & 9 & 1 & 1 & 3 & 3 & 9 & 1 & & \\
C7 & 4.2316 & & 9 & & 3 & & & 3 & 3 & 3 & 3 & & 3
\end{tabular}




\section{Fuzzy Computation}

Normal Fuzzy Number, Trapezoidal Fuzzy Number and Triangular Fuzzy Number are commonly used in the study of fuzzy theory. In this study, Triangular Fuzzy Numbers are used to conduct calculation. For example, When L1 curriculum corresponds to the $\mathrm{C} 1$ criterion, its fuzzy process is as follows: $\sum_{j}^{8} A 1 \mathrm{jXj}=(4.0861 \times 0.00 ; 4.0861 \times 0.10 ; 4.0861 \times 0.40)$

In the research, when the fuzzification step is completed, it needs to be converted into a crisp value by the calculation of Defuzzification. In this state, the author would use the Center of Gravity Method to get the weight value after defuzzification. Compared with other methods, the Center of Gravity Method is simple in calculation and does not have the personal preferences of decision makers. The calculation method of Center of Gravity Method is:

Set: $A=(L, M, U)$

$\mathrm{DF}=(\mathrm{U}-\mathrm{L})+(\mathrm{M}-\mathrm{L}) / 3+\mathrm{L}$

In this study, all the finer items were calculated by using this method and the final weight was obtained by combining the centroid method with defuzzification.

\section{Research results and discussion}

By using the research method of Fuzzy QFD, the weight values of 14 environmental design courses were finally obtained, which are listed in Table 4.

Table 4.

fuzzy weight values

\begin{tabular}{ccc}
\hline & Weight values & Ranks \\
\hline L1 & 3.1053 & 6 \\
L2 & 2.5307 & 8 \\
L3 & 2.4075 & 10 \\
L4 & 2.2958 & 12 \\
L5 & 1.8876 & 13 \\
L6 & 2.3933 & 11 \\
L7 & 3.0747 & 7 \\
L8 & 3.6835 & 5 \\
L9 & 4.7851 & 1 \\
L10 & 4.331 & 3 \\
L11 & 4.263 & 4 \\
L12 & 2.5071 & 9 \\
L13 & 1.5944 & 14 \\
L14 & 4.5997 & 2 \\
\hline
\end{tabular}

From the research results, we can find that in the course of environmental design, the highest weight value is L9.Environmental Thematic Design, and the lowest weight value is L13.Engineering Budget.

From the weight value of all courses, the courses with higher weight than 4 are: L9.Environmental Thematic Design, L14.Design Planning, L10.Regional Environmental Design, L11.Landscape Planning and Design. Courses with weights between 3 and 4 include: L8.Model Design and Production, L1.Basic Painting, L7.Public Interior Design. Courses with weights between 2 and 3 include: L2.Composition, L12.Lighting Design, L3.History of Design, L6.Ergonomics, L4.Basic Drawing. The courses with weights between 1-2 are: L5.Computer Aided Design and L13.Project budget. Details are shown in Table 5.

Table 5. interval of each range

\begin{tabular}{cc}
\hline Interval & Number \\
\hline 4 or more & L9、L14、L10、L11 \\
$3-4$ & L8、L1、L7 \\
$2-3$ & L2、L12、L3、L6、L4 \\
$1-2$ & L5、L13 \\
\hline
\end{tabular}

\section{Conclusion and Suggestion}

This study combines the KJ method with literature review to sort out eight kinds of designer's perceptions of professional ethics and code of conduct. The author produced a questionnaire to investigate the designer's perceptions of professional ethics and code of conduct, and used descriptive statistics to calculate the average of eight perceptions. In this study, Fuzzy and QFD are combined to solve the problem of cognitive uncertainty to the greatest extent, so as to obtain more accurate weights. Fuzzy theory also has further improved the accuracy of QFD calculation results, and at the same time solved the subjective evaluation problem of experts to a certain extent, which also helps to make the results clearer.

The research results are divided into four sections. According to the results, we suggest that more professional ethics education should be added to those courses with a weight of more than 4 for that these courses connect the most to the design work and can easily affect the professional ethics behavior of the design work.

\section{References}

[1] S. Liu, Y. Lee, Y, Lin \& C. Tseng, "Applying quality function deployment in industrial design curriculum planning". International Journal of Technology and Design Education, 23(4), 2013, pp. 1147-1160.

[2] ABET."Criteria for accrediting engineering programs: Effective for reviews during the 2014-2015 accreditation cycle". 2013.Retrieved from http://www.abet.org

[3] I. Brassington, "On the Relationship between Medical Ethics and the Law". Medical Law Review, 26(2), 2018, PP. 225-245.

[4] Liu, Zhang, Lai, \& Wang, "A novel method of design elements based on EGM and fuzzy QFD".International Journal of Product Development, 22(5), 2018, pp. 408-420.

[5] Akao, Y. (1990). Quality function deployment: Integrating customer requirements into product design. Translated by 
Glenn Mazur. Cambridge, MA: Springer.

[6] G. Liang, "Applying fuzzy quality function deployment to identify service management requirements for customer quality needs". Quality \& Quantity, 44 (1) (2010), pp. 47-57

[7] Chen, Yeh, Pai, \& Chen, "Integrating Refined Kano Model and QFD for Service Quality Improvement in Healthy Fast-Food Chain Restaurants". International Journal of Environmental Research and Public Health, 15(7), 2018, 1310.

[8] Liu, SF, Cheng, JH, Lee, YL, Gau, FR, "A case study on FMEA-based quality improvement of packaging designs in the TFT-LCDindustry". Total Quality Management. 27(4), 2016, pp, 413-431.

[9] M. Tavana, M. Yazdani, D. Di Caprio, "An application of an integrated ANP- QFD framework for sustainable supplier selection". International Journal of Logistics Research and Applications, 20(3), 2017, pp. 254-275.

[10] L. Zadeh, "Fuzzy sets". Information and Control, 8, 1965, pp. 338-353.

[11] K. Mazher, A. Chan, H. Zahoor, M. Khan, \& E. Ameyaw, "Fuzzy Integral-Based Risk-Assessment Approach for Public-Private Partnership Infrastructure Projects". Journal of Construction Engineering and Management, 144(12), 2018, 04018111.

[12] D. Singh, and R. Tiong. "A fuzzy decision framework for contractor selection.” J. Constr. Eng. Manage. 131 (1), 2005, pp. 62-70.

[13] ICOGRADA, ICSID, \& IFI, Model Code of Professional Conduct for Designers. 1987. Retrieved from http://www.ifiworld.org/index.cfm?GPID=33

[14] ICSID, Professional Ethics ICSID Code of Professional Ethics. 2008. Retrieved from http://ingles.duoc.cl/sl/ethics/pdf/Professional.pdf

[15] IDSA, Code of Ethics. 2008. Retrieved from http://www.idsa.org/absolutenm/templates/ $\mathrm{a}=57 \& \mathrm{z}=0$

[16] ASID, ASID Code of Ethics and Professional Conduct. 2006. Retrieved from http://www.asid.org/find/ASID+Code+of+Ethics+and+Pro fessional+Conduct. Htm

[17] AGDA, Code of Ethics. 2008. Retrieved from http://www.agda.com.au/about/code

[18] DIA, Code of Ethics. 2008. Retrieved from http://www.design.org.au/content.cfm?id=35 